\title{
A AFIRMAÇÃO DOS ÍNDIOS NO NORDESTE!
}

Edson Silva*

APRECIAÇÃO

A presença indígena no Nordeste: processos de territorialização, modos de reconhecimento e regimes de memória. João Pacheco de Oliveira (Org.) Rio de Janeiro, Contra Capa, 2011, 732 p.

A ideia desse texto não é fazer propriamente uma resenha do recém-publicado livro $A$ presença indígena no Nordeste: processos de territorialização, modos de reconhecimento e regimes de memória, pois uma resenha diante da dimensão do conjunto de textos que compõe 0 livro é uma tarefa bastante árdua e demandaria um espaço bem maior dos limites que aqui propomos. Buscamos tão somente então situar o livro em um debate mais amplo: as pesquisas, as reflexões e os textos gerais publicados sobre os índios no Nordeste.

Com suas mobilizações os índios no Nordeste vêm ocupando cada vez mais o cenário sociopolítico regional e assim questionando as tradicionais visões e imagens que advogam a inexistência, a extinção ou ainda o gradual desaparecimento dos povos indígenas na Região. Durante muito tempo e até bem recentemente, os indígenas no Nordeste não foram desconsiderados nas reflexões históricas, antropológicas e das Ciências Humanas e Sociais em uma visão baseada nas concepções da aculturação ou mestiçagem, após a extinção oficial dos aldeamentos indígenas a partir de meados do Século XIX.

No Nordeste, sobretudo após a Lei de Terras de 1850 que determinou os registros cartoriais das propriedades, definiu as terras devolutas oficiais que poderiam ser vendidas em leilões públicos, os senhores de engenho no litoral, os fazendeiros no interior, os tradicionais invasores das terras dos antigos aldeamentos indígenas bem como as autoridades defensoras que possuíam interesses comuns, sistematicamente afirmaram que os índios estavam "confundidos com a massa da população" e por esse motivo não existiam razões para continuidade dos aldeamentos.

Com a determinação oficial para extinção dos aldeamentos e no ato de medir, demarcar e lotear com destinação de pequenas glebas de terras para umas poucas famílias, os arrendatários e invasores tiveram suas posses legitimadas. Muitos indígenas migraram para as periferias urbanas, dispersaram-se pelas regiões vizinhas aos aldeamentos, outros passaram a

*Doutor em História Social pela UNICAMP. Leciona no Programa de Pós-Graduação em História/UFPE, no Programa de Pós-Graduação em História/UFCG (Campina Grande-PB) e no Curso de Licenciatura Intercultural Indígena na UFPE/Campus Caruaru, destinado a formação de professores/as indígenas. É professor de História no CENTRO DE EDUCAÇÃO/Col. de Aplicação-UFPE/Campus Recife. E-mail: edson.edsilva@gmail.com 
trabalhar "de alugado" em suas próprias terras agora nas mãos de fazendeiros, e umas poucas famílias permaneceram nos "sítios", pressionadas ao longo do tempo por fazendeiros. Assim, a partir das últimas décadas do Século XIX, ocorreu um silêncio oficial sobre os índios no Nordeste.

Os habitantes dos lugares onde existiram antigos aldeamentos passaram a ser chamados de caboclos, condição essa muitas vezes assumida pelos indígenas para esconder a identidade étnica diante das inúmeras perseguições. A essas populações foram dedicados estudos sobre seus hábitos e costumes, considerados exóticos, suas danças e manifestações folclóricas, consideradas em vias de extinção. Como também aparecerem nas publicações de escritores regionais, cronistas e memorialistas municipais que exaltam de forma idílica a contribuição indígena nas origens e formação social de cidades do interior do Nordeste.

A imagem do caboclo aparece em obras literárias sobre fatos pitorescos, recordações, "estórias" das regiões Agreste e Sertão nordestino. Como personagens típicos e curiosos que buscavam se adaptar às novas situações de sem-terras, vagando em busca de trabalho para sobrevivência. Escritores renomados, intelectuais e pesquisadores como Gilberto Freyre, Raquel de Queiroz, Câmara Cascudo, José Lins Rego, Graciliano Ramos, Jorge Amado, só para citar alguns dentre os mais conhecidos, em seus escritos quando se referiram aos indígenas remetem a um passado idílico e omitiram a presença indígena contemporânea no Nordeste.

Os povos indígenas no Nordeste, que retomaram suas mobilizações desde as primeiras décadas do século XX, conquistaram o reconhecimento do Estado brasileiro com a instalação de postos indígenas pelo Serviço de Proteção aos Índios/SPI, ainda que a atuação deste órgão governamental na Região tenha sido muito assistencialista e não garantido as terras indígenas. Os atuais povos indígenas questionam, portanto, as reflexões sedimentadas no desaparecimento indígena na Região e se constituem em um desafio, uma demanda para compreensão dos processos históricos que resultam nas mobilizações sociopolíticas atuais pelas reivindicações, conquistas e garantias de seus direitos.

Do ponto de vista dos estudos, pesquisas e publicações com uma abordagem geral sobre os índios na Região, em 1935 o antropólogo Estevão Pinto publicou Os indígenas do Nordeste, na renomada Coleção Brasiliana da Editora Nacional. O primeiro volume tem como subtítulo "Introdução ao estudo da vida social dos indígenas do Nordeste brasileiro". Trata-se de uma minuciosa pesquisa bibliográfica e documental ilustrada com mapas, quadros e fotografias. O segundo volume, trazendo o subtítulo "organização dos indígenas do Nordeste brasileiro", veio a público em 1938 e, além de mapas e quadros, trouxe diversos desenhos, gravuras e estampas, reproduzidas de livros de viajantes que estiveram no Brasil. Esse volume é baseado 
principalmente nas informações dos cronistas coloniais e viajantes, tratando, em quase sua totalidade, dos tupis no litoral.

A obra Os indígenas do Nordeste recebeu efusivas acolhidas de estudiosos da época, dentre os quais Gilberto Freyre, Pedro Calmon, o antropólogo Herbert Baldus, que publicaram resenhas críticas, elogiosas a erudição, capacidade de interpretação e síntese do autor. Com a obra, o alagoano Estevão Pinto, mas com a trajetória profissional em Pernambuco, passou a ser conhecido no Brasil e no exterior, realizando conferências, participando de congressos, publicando artigos.

Estevão Pinto que realizava estudos sobre os índios Fulni-ô (Águas Belas/PE), seria nos próximos anos pesquisador e antropólogo da Fundação Joaquim Nabuco, dirigida por Gilberto Freyre, de quem era muito próximo, e principalmente de suas ideias a respeito da mestiçagem, foi adepto das concepções da aculturação e assimilação das populações indígenas com ênfase na progressiva caboclização. Em Os índios do Nordeste o autor expressou o que reafirmará em escritos posteriores, a exemplo do livro Etnologia brasileira: Fulniô, os últimos tapuias publicado em 1966, sua visão sobre o desaparecimento paulatino dos índios e a crença em sua total extinção.

Embora não seja específico sobre os índios no Nordeste, o livro Os índios a civilização com o subtítulo "a integração das populações indígenas no Brasil moderno", do antropólogo Darcy Ribeiro teve a primeira edição publicada no Brasil em 1970. No capítulo "Os índios do Nordeste" o autor fez uma retomada histórica sobre os processos de esbulhos das terras indígenas na Região. Ao tratar dos indígenas que habitavam no Sertão do São Francisco o antropólogo afirmou que em função da expulsão dos seus territórios, os índios se dispersaram, vivendo, no início do século XX, "aos bandos que perambulavam pelas fazendas, à procura de comida". E de forma pejorativa e talvez sarcástica, completou: "vários magotes desses índios desajustados eram vistos nas margens do São Francisco" (1982, p.56).

São bastante conhecidas as concepções de genocídio e etnocídio sobre a história dos povos indígenas no Brasil, defendidas por Darcy Ribeiro. $O$ autor também advogou as "etapas da integração", para os povos indígenas existentes nas áreas mais antigas da colonização português a exemplo do Nordeste. As categorias de índios "integrados" e de "grau de integração na sociedade nacional" foram atribuídas aos grupos indígenas que se encontravam no século XX "ilhados em meio à população nacional", como também a ideia da aculturação e assimilação dos índios a sociedade nacional.

Em nota na Introdução de Os índios e a civilização, o autor afirmou que o livro era resultado do relatório de pesquisas realizadas desde 1952, que parcialmente publicara em 1958 
e com versões de alguns dos capítulos divulgadas em revistas nacionais e internacionais, nos anos seguintes. Cabe lembrar ainda que Darcy Ribeiro foi funcionário do SPI, órgão estatal cuja concepção e atuação se fundamentava nos cânones positivistas, na proteção fraternal dos índios, atuando para integrá-los pacificamente ao mundo dos não-índios e portanto concebendo que ser índio era uma condição transitória e não respeitada. Sendo ainda Darcy Ribeiro um grande admirador das ideias e da pessoa do Marechal Rondon o fundador do SPI, a quem 0 antropólogo dedicou Os índios e a civilização.

Observemos que o citado livro com seu o titulo binário expressa oposições explícitas: "os índios" e a "civilização". Ou mais sutis: os índios atrasados que se integram no "Brasil moderno". Foi então a partir dessa perspectiva que o antropólogo pensou e escreveu sobre os povos indígenas na história do país. A ideia de um Brasil moderno formado por uma macroetnia, o povo brasileiro, que aparece em Os índios e a civilização foi retomada e defendida pelo autor em estudos posteriores. Na perspectiva de Darcy Ribeiro os povos indígenas, mesmo aqueles considerados "isolados", enquanto microetnias em nada influenciariam a História e a configuração do país, muito menos os "integrados"!

Os méritos de Darcy Ribeiro decorrem de ter sido o primeiro autor que discutiu 0 "problema indígena" de uma forma ampla, e por sua explícita posição política em denunciar as opressões sobre os índios na História do Brasil, o que tornou as ideias do antropólogo bastante conhecidas. Os índios e a civilização, livro com várias edições, por sua quantidade de informações e sistematização de dados, ainda que guardada as necessárias ressalvas, continua sendo uma leitura necessária para se conhecer parte da história das populações indígenas no país. Além de ter sido traduzido para outras línguas, adotado nos diversos cursos de Ciências Sociais e Humanas no Brasil, formando uma geração de estudantes, foi também lido por profissionais de outras áreas e pelo público em geral. As ideias desse livro a respeito dos índios no Nordeste, em muito influenciaram a visão de outros estudiosos e o senso comum sobre os índios e suas expressões socioculturais na Região.

A Coleção Índios do Nordeste: temas e problemas, atualmente com 12 volumes, vêm sendo publicada desde 1999 pela Editora da Universidade Federal de Alagoas (EDUFAL). Os livros dessa série, embora boa parte dos volumes seja estudos dedicados aos índios em Alagoas, são coletâneas de textos publicados por autores que pesquisam os povos indígenas no Nordeste. Todavia não percebemos uma preocupação na discussão teórica mais aprofundada sobre o conjunto dos textos publicados em cada volume. E um estudo sobre os significados dessa Coleção para a reflexão a respeito dos índios no Nordeste ainda estar por ser realizado. 
O livro A viagem da volta: etnicidade, política e reelaboração cultural no Nordeste indígena, organizado pelo antropólogo João Pacheco de Oliveira (UFRJ/Museu Nacional) e publicado em 1999 (2ª edição, 2004), marcou decisivamente as mudanças ocorridas nos atuais estudos sobre os povos indígenas no Nordeste. Em um instigante texto introdutório o organizador a partir dos conceitos situação colonial, territorialização e fluxos culturais, propôs uma etnologia sobre os chamados "índios misturados" no Nordeste, situando as discussões nos artigos que compõem a coletânea. O livro é, portanto, uma coletânea de textos que problematiza as práticas discursivas nos processos históricos de esbulhos das terras dos aldeamentos, enfatizando as mobilizações indígenas contemporâneas pelas afirmações das identidades étnicas e reivindicações de seus territórios. Os artigos desse livro são reflexões de estudos acadêmicos para o mestrado e doutorado, em sua maioria orientados pelo organizador, e resultaram na feliz conjugação de abordagens baseadas nas pesquisas antropológicas, sociológicas e históricas.

Já o livro A presença indígena no Nordeste: processos de territorialização, modos de reconhecimento e regimes de memória, consolidou definitivamente os povos indígenas na Região como um tema de estudos. A publicação desse livro com mais 10 anos após a $1^{a}$ edição da coletânea $A$ viagem da volta, representa um esforço de reunir textos das mais recentes pesquisas e reflexões sobre o assunto. Confirmando, portanto, que os interesses pelos estudos a respeito dos índios no Nordeste não só continuaram ao longo do período, como foram ampliados e se diversificaram.

Essa alentada nova coletânea com 24 textos que retomam abordagens sobre os índios no Nordeste enquanto sujeitos históricos ao longo da História do Brasil. E como se lê na Apresentação, o livro "decorre do desconforto e mesmo indignação que gera num conjunto de pesquisadores a forma superficial e preconceituosa com que a existência indígena no Nordeste", o que é expresso diuturnamente com muita força pelos meios de informações com consequências danosas no conhecimento sobre os povos indígenas entre estudantes, na formação da opinião pública e no senso comum em geral.

Trata-se sem dúvidas de uma significativa contribuição para compreensão da participação dos povos indígenas nos processos históricos no Nordeste, e por essa razão uma leitura imprescindível para todos aqueles/as que se empenham com seriedade em conhecer e estudar a história da Região na perspectiva das mudanças sociais que se fazem necessárias, onde os povos indígenas foram, são e serão atores sociopolíticos atuantes e importantes. 


\section{Referências}

1. OLIVEIRA, J. P. de. (Org.). A viagem de volta: etnicidade, política e reelaboração cultural no Nordeste indígena. $2^{\mathrm{a}}$ ed. Rio de Janeiro, Contra Capa, 2004.

2. PINTO, Estevão. Os indígenas do Nordeste: introdução ao estudo da vida social dos indígenas do Nordeste brasileiro. São Paulo: Nacional, 1935, v.1.

3. Os indígenas do Nordeste: organização e estrutura social dos indígenas do Nordeste brasileiro. São Paulo: Nacional, 1938, v. 2.

4. E__ Etnologia Brasileira: Fulniô os últimos tapuias. São Paulo, Nacional, 1956.

5. RIBEIRO, Darcy. Os índios e a civilização: a integração das populações indígenas no Brasil moderno. $4^{\mathrm{a}}$ ed. Petrópolis, Vozes, 1982. (a primeira edição brasileira é de 1970).

6. SILVA, Edson. Xukuru: memórias e história dos índios da Serra do Ororubá (Pesqueira/PE), 1959-1988. Campinas, UNICAMP, 2008. (Tese Doutorado História Social) 